\title{
Consumption through the Ambivalent Prism of Intergenerational Support
}

The family plays an important role in coping with financial adversity (e.g., Hamilton, 2009; Hill, 1991), but previous studies have largely neglected the role of ambivalence in family sharing and adult intergenerational relationships (e.g., Belk, 2007/2010/2014; Belk \& Llamas, 2012). Past consumer research on low-income parents of underage children emphasised parental altruism and sacrifice (e.g., Cappellini, Marilli, \& Parsons, 2014; Ruth \& Hsiung, 2007), focused on love and solidarity (e.g., Hamilton \& Catterall, 2006; Kochuyt, 2004) and the avoidance of conflict (e.g., Hamilton, 2009), and presented a more positive view of how families cope with financial difficulties. Conversely, consumer research on homeless individuals suggested a bleaker picture characterised by family neglect, abuse, and lack of love as factors that lead to homelessness (e.g., Hill, 1991; Hill \& Gaines, 2007). These somewhat polarised views of the family potentially overlooked the ambivalent feelings that arise in family relationships. The sociological concept of intergenerational ambivalence (i.e., mixed feelings, both positive and negative, that often accompany adult intergenerational support and sharing with adult family members) offered a more nuanced view of family life that moved beyond these opposing viewpoints of love, solidarity and harmony against conflict, disappointment, and neglect (e.g., Lüscher, 2011; Lüscher \& Pillemer, 1998). The study herein uses the experiences of downwardly mobile Greek consumers faced with financial difficulties to explore ambivalence, intergenerational support and family sharing ${ }^{1}$. The next sections review relevant literature on sharing, familial intergenerational support, intergenerational ambivalence and family identity, and ambivalence in sharing.

\section{Sharing}

Previous work on sharing suggested that sharing can be difficult (Belk 2007/2010; Belk \& Llamas, 2012). Belk (2007) specifically acknowledged anti-sharing phenomena within the family, i.e., the atomization of former family possessions like televisions, cars and meals. Belk (2010) referred to forced compliance and debt when sharing. Belk and Llamas (2012) reported unpleasant experiences and dilemmas when sharing due to the desire for intimacy and belongingness that drives sharing, and to the desire for material independence and

\footnotetext{
${ }^{1}$ Sharing is "the act and process of distributing what is ours to others for their use and/or the act and process of receiving or taking something from others for our use" (Belk 2007, 126). Support refers to the provision of financial, emotional and practical assistance to others. When we support others, we share our resources and engage in one type of sharing.
} 
possessiveness that resists sharing. However, consumer research has largely neglected the role of ambivalence in family sharing, particularly relative to adult intergenerational support.

\section{Familial intergenerational support and sharing}

Consumer research has tended to concentrate on the nuclear family and on the taken-forgranted, obligatory sharing that takes place within families with underage children (e.g., Carrigan \& Szmigin, 2006; Epp \& Price, 2008/2010; Thompson, 1996), though some research examined more diverse family constellations, such as empty-nest families (Hogg, Curasi, \& Maclaran, 2004). Further research considered relationships between adult children and their parents or grandparents, and explored intergenerational influence on consumer behaviour (e.g., Mittal \& Royne, 2010), but largely overlooked the influence of intergenerational support on adult consumption experiences. Nevertheless, research has shown that intergenerational sharing that includes the provision of practical and financial aid to adult family members is widespread. Globally, a significant number of adult children have returned to or remain in their parental homes or receive parental financial support, and adults are providing assistance to grandchildren or aging parents (Bengtson, 2001; ONS, 2014). As Belk (2010) briefly mentioned "Intergenerational sharing outside of the home and immediate family is quite common both upward to parents and downward to adult children and grandchildren." (p.725), but subsequent work on sharing (e.g., Belk, 2014), does not refer to

or empirically examine adult intergenerational, upward or downward sharing. Nevertheless, intergenerational sharing and how it mediates the consumption experiences of both adult recipients and providers of resources in economically challenging times are important topics for consumer researchers and marketing managers.

\section{Intergenerational ambivalence}

Intergenerational support and sharing are potential breeding grounds for ambivalence in family relationships and consumption. This is because intergenerational support is associated not only with affection, compassion for others and mutual aid, but also with failed expectations for adult children's financial independence, conformity pressures, the sacrifice of autonomy and the desire to exercise control. Sociological research highlights the concept of intergenerational ambivalence (e.g., Lüscher, 2011; Lüscher \& Pillemer, 1998; Willson, Shuey, \& Elder, 2003), i.e., mixed feelings that occur due to tensions in adult intergenerational relationships. For example, tensions may exist between dependence and 
ideals of independence, or between self-interest and other-orientation. The intergenerational ambivalence paradigm challenges the solidarity and conflict paradigm in which the family is characterised by situations that produce either positive or negative feelings. According to the ambivalence perspective, both pleasant and unpleasant experiences can occur in family relationships, often simultaneously. However, consumer research has not explored ambivalence in familial intergenerational sharing.

\section{Family identity and ambivalence in sharing}

According to consumer research, the concepts of love (e.g., Hogg et al., 2004), conflict avoidance (e.g., Götze, Prange, \& Uhrovska, 2009), and conflict resolution (e.g., Olsen \& Grunert, 2010) within families, including those consumers with low incomes (e.g., Cappellini et al., 2014; Hamilton \& Catterall, 2006), create a largely positive view of family life. However, Epp and Price (2008) discussed how each family accommodates interacting bundles of identities that may be inconsistent with one another under some circumstances (thus suggesting a less harmonious view of family life). These identity bundles include the family's collective identity, relational identities (e.g., parent-child dyads), and individual family members' identities. However, Epp and Price (2008/2010) did not explore ambivalence in family sharing that may reflect inconsistent family identity bundles. Family identity both influences and is influenced by ambivalence in sharing. Otnes et al. (1997) described consumer ambivalence as

'the simultaneous or sequential experience of multiple emotional states, as a result of the interaction between internal factors and external objects, people, institutions, and/or cultural phenomena in market oriented contexts, that can have direct and/or indirect ramifications on pre-purchase, purchase or post-purchase attitudes and behavior' (p.82).

Otnes et al. (1997) explored antecedents to consumer ambivalence and coping strategies but did not examine ambivalence within the context of family sharing. Only a few studies have considered ambivalence within the family even though consumers' mixed emotions have been identified as salient in the marketplace when shopping, consuming, and watching advertisements (e.g., Olsen, Prebensen \& Larsen, 2009; Penz \& Hogg, 2011; Sabri, 2012); and consumers can experience ambivalent feelings because of conflicts between selfindulgence and caring for family members (Thompson, 1996). These earlier studies attributed 
a consumer's ambivalent feelings to self/others tensions, to conflicting desired and undesired selves and to family liminality (Karanika \& Hogg, 2010; Stevens et al., 2003; VOICE Group, 2010), and did not focus on sharing or on consumers involved with adult intergenerational support who were experiencing significant downward mobility. The experiences of downwardly mobile consumers who previously enjoyed a good standard of living but then coped with financial adversities and engaged in intergenerational support may differ significantly from the (expectant) mothers who were the subjects of earlier studies. As the Voice group (2010) suggested, financial constraints can generate consumption ambivalence and, as sociological research suggests, adult intergenerational support can generate intergenerational ambivalence. Yet consumer research has largely overlooked the role of ambivalence in family sharing (e.g., Belk, 2007/2010/2014; Belk \& Llamas, 2012), and particularly the role it plays in adult intergenerational support during times of economic adversity.

\section{METHODOLOGY}

\section{Research context - The changing Greek context}

This study examines the experiences of downwardly mobile Greek consumers who were involved in adult intergenerational support and sharing. In Greece, as in other Southern European countries, factors such as late industrialisation and relatively recent non-democratic rule have resulted in a weak welfare state where social risks (e.g., unemployment, illness) are assumed to mainly be the responsibility of the family and kinship networks (Gal, 2010). The state intervenes with only relatively low monetary benefits. This resonates with the traditional significance of ipokhreosi, or obligation, as the ethical nexus of all social relations in Greece and with the traditional Greek value of philotimo that defines appropriate behaviour toward others. Philotimo (literally means love of honour) refers to the consistency of an individual's behaviour within his assigned role as an integral part of a greater entity, and with the preservation of the public image this demands. It refers to experiencing oneself as part of a system of group relatedness. It reflects the inherent sociality of the self (Arnould \& Rose, 2015), and can affect resource circulation. Behaviour which violates philotimo brings shame upon the individual and his membership groups (e.g., Pollis, 1965). 
However, the experience of living in less economically difficult times during an era of increased globalisation raised the aspirations of and expectations for adult children's financial independence in Southern European countries (e.g., Georgas et al., 2001). Scholars have discussed how Greece transitioned from collectivism to individualism (e.g., Georgas, 1989), particularly in urban areas, and moved from the extended to the nuclear family system (Papadopoulos, 1998). This individualisation arose from urbanisation and industrialisation, and was facilitated by both integration in the European Union and transnational influences like global exposure to mass media, tourism and cultural exchanges (Georgas, 1989; Kouremenos \& Avlonitis, 1995). Greece became a largely urban society in the early 1960s, and traditional life quickly eroded. The onset of higher education levels and social mobility made the emerging generation less dependent on the family (Stewart, 2014). Until then, a word for 'privacy' did not exist in the Greek language, demonstrating the absence of the concept of an autonomous individual (Pollis, 1965); such a word now exists (Babiniotis, 2005). Hirschon (2001) discussed how contemporary Greek culture came to place a premium on personal autonomy, which conflicted with the emphasis traditionally placed on values promoting solidarity (and resonating with the Christian roots of the Greek culture). The tension between personal autonomy and group (family) solidarity may be one of the sources of intergenerational ambivalence within intergenerational support. According to Stewart (2014), most Greek people are both individualists and group-orientated to varying degrees, in alternation, and according to the situation.

Moreover, urbanisation and industrialisation in Greek society in past decades have resulted in a consumer culture, with store displays, mass media and advertising providing exaggerated consumption images. Such images (along with greater discretionary income and access to consumer credit) have encouraged a democracy of consumer aspirations and desires (e.g., Kouremenos \& Avlonitis, 1995). However, Greece has proven to be particularly vulnerable to the global recession and unable to handle the inherited debt. As a member of the European Union (EU), Greece asked for support from the EU and the International Monetary Fund, which resulted in a sequence of austerity measures that dramatically affected the everyday lives of Greek citizens. The major recession in Greece is currently generating significant reductions in salaries, pensions, and other sources of income, weakening job security (with frequent downward revisions to wage agreements), causing significant job cuts, increasing unemployment and fears of losing one's job, and resulting in burdensome working arrangements (Eurostat, 2012/2013/2014). VAT has increased from 17\% to 23\%. Political 
transformations have also taken place. The previously largest political parties have lost considerable support due to people's lack of trust in politicians. For example, in 2009, the Greek Socialist Party received $43.9 \%$ of the Greek vote and won the elections, whereas in the 2012 June elections the percentage dropped to $12.28 \%$, and even further in 2015 to $4.68 \%$. In 2009, the Coalition of the Radical Left won $4.6 \%$ of the vote, which increased in 2012 to $26.89 \%$ and in 2015 to $35.34 \%$ when they won the elections campaigning on an anti-austerity platform. The popularity of the Greek far-right, described as a fascist party (Golden Dawn; third party in the parliament), has increased dramatically. In 2009 they received only $0.29 \%$ of the vote but this increased in 2012 to $7 \%$ and remained fairly steady in 2015 at $6.28 \%$. It has been suggested that angry Greeks voted for this party to punish the politicians in power (Chalari, 2014).

The last five years, Greece has suffered from not only an economic squeeze, but also prolonged financial and socioeconomic uncertainty. Whether or not Greece can remain in the economic and monetary union of EU remains uncertain (e.g., Gnath \& Hoffmann, 2015).Summer 2015 sawprotracted negotiations on new bailout conditions (including the restructuring its debt) in order to secure Greece's position in the eurozone and within the EU more broadly. . Greece and its creditors agreed on a third bailout, which imposed further spending cuts on the country in order to avoid bankruptcy and exit from the Eurozone. However, this might yet prove to be only a short-term solution to keep Greece in the Eurozone and might not be the basis for a viable longerterm solution. It could be that the austere conditions being imposed only postpone the problem (Gnath \& Hoffmann, 2015), creating an unstable scenario that might yet lead to the exit of Greece from the euro area.

More specifically, on 27 June 2015, following meetings between Greece and its creditors, the Greek Prime Minister, Alexis Tsipras, called for a referendum asking the Greek voters to decide whether or not they approved of the latest proposal for programme continuation by Greece's creditors.At the same time the Greek government introduced capital controls. The amount of money Greek people could withdraw was restricted to $€ 60$ per day per debit card. Card payments and online transactions in Greece were allowed but not any payments to accounts abroad. These announcements about capital controls resulted in panic withdrawals and a tightening up on business transactions that affected sectors such as retail sales, and the commercial activity and industry of the country as a whole. 
Tsipras asked the Greek electorate to reject the June 2015 proposal, claiming that a 'No' vote in the referendum would pressure EU partners and creditors into mitigating the severity of their proposals. However, the German Finance Minister, Schäuble, argued that negotiations after the referendum-regardless its result-would re-start completely from the beginning and would involve tougher conditions. Indeed, the threat of the imminent collapse of the Greek economy seemed to be exacerbated because thelenders' proposals were much tougher after the referendum result. (Mavrozacharakis \& Tzagarakis, 2015). Inthe referendum Greece voted 61\% 'No', and 38\% 'Yes'. The Greek Finance Minister, Yanis Varoufakis, resigned. Tsipras surprised many when he made a U-turn after the bailout talks came so close to collapse. He asked the Greek parliament to sign up to an even harsher package less than a week after the referendum. Greek citizens now have to accept a package that is much tougher (by $€ 4$ billion) than the one they rejected in the referendum. Overall, the economy continues to stagnate with little evidence of growth, in fact the economy is expected to continue to shrink (Traynor 2015). The capital controls are felt to be an unwarranted attempt to strangle the economy. The creditors are also dissatisfied. The negotiating partners continue to be suspicious of each other. The euro area remains stuck in a crisis (Gnath \& Hoffmann, 2015) as negotiators on both sides try to achieve agreement on bailout terms.

Therefore, Greece was additionally chosen as the empirical context of this study because prior research on low-income consumers has been conducted in subsistence markets (e.g., Ruth \& Hsiung, 2007), and more affluent societies (e.g., Elliott, 1995; Hill, 1991), but the experiences of mainstream consumers transitioning into lower consumption levels within a context of increased socioeconomic difficulty (and uncertainty) have been relatively neglected. Several societies (e.g., Spain, Portugal, Italy, Ireland), however, have recently experienced severe economic difficulties and austerity measures impacting lifestyles and consumption; and despite the more recent upturn in these economies, unemployment rates (particularly among young workers) remain high (e.g., Spain, Italy; Eurostat, 2014). This paper therefore examines Greek middle-class consumers' transitions into lower consumption levels, intergenerational support and family sharing to understand consumption experiences within the context of families and family members attempting to cope during periods of socioeconomic difficulty.

\section{Research design and method}


In answer to Askegaard and Linnet's (2011) call for more context-attentive phenomenological studies, this study captured middle-class Greek consumers' experiences with lower levels of consumption. It concentrated on a relatively small number of participants (e.g., Carrigan \& Szmigin, 2006; Kerrane \& Hogg, 2013), and utilised snowball and convenience sampling to identify 35 participants (17 men, 18 women), aged 22-69, who were experiencing lower consumption levels due to financial difficulties (Miles \& Huberman, 1994). Based on their education levels and occupational roles, participants belonged to a broad urban middle class in Greek society, but were experiencing significant income reductions and problems making ends meet. Participants lived in Thessaloniki, the second largest city in Greece, which also has one of the highest unemployment rates in the country. Due to space limitations, the stories of 21 participants were used and these reflect the findings of the whole dataset. Their personal characteristics are summarised in Table 1.

\section{Table 1 here}

Existential phenomenology was chosen as it emphasises the perspective of the experiencing individual aimed at understanding consumers' experience as it is lived (Kvale, 1983; Thompson et al., 1989). Phenomenological interviews were semi-structured with informants largely driving the conversations (Kvale, 1983; Thompson et al., 1989). Informants were informed that interviews would be audio-taped and anonymity was assured. They were invited to talk about themselves and their families, describe the changes they had made to their lifestyles and consumption, and discuss the possessions, products, and consumption activities that were meaningful to them as well as those they now avoided or had abandoned.

The research team consisted of the first author who is Greek and the second author who is British. The interviews were conducted in Greek by the first author who brought to the process her experience of living in Greece during her upbringing and earlier life and currently living in the UK for a decade. Establishing rapport with the participants was facilitated by the fact that the researcher is also Greek but this also entailed some potential threats to the quality of the data. Seeing the interviewer as 'one of them', meant that some participants sometimes expected her to understand their perspective and without being probed would keep their descriptions short, saying for example 'you know what I mean' or 'you know how things are in Greece'. To overcome this potential threat to the data quality, the interviewer had to probe by saying 'I would like to know more about how you experience this...' or by saying 'I have been living abroad for several years and I would like to know about your experience'. The 
transcription and translation to English was conducted by two professional translators and were checked by the first author. The interpretive analysis was conducted by both authors and benefitted from both insider and outsider perspectives as the interpretive team is multicultural.

A phenomenological-hermeneutical analysis was undertaken (Thompson et al., 1989). Each interview was interpreted at the individual level and, in an iterative process, 'parts' of the data were interpreted and reinterpreted in relation to the developing sense of the 'whole' (Thompson et al., 1989). Separate interviews were then related to each other and points of difference and common meanings were identified (Thompson et al., 1989). Hence, the developing thematic structure was continuously challenged and revised. An emic approach was primarily used which relied on participants' own terms/categories. Then an etic interpretation linked the emic meanings to broader theoretical terms.

\section{FINDINGS AND DISCUSSION}

Strong intergenerational support and sharing emerged within participants' families. It took the forms of financial support, the provision of housing and practical support (e.g., childminding, cooking, doing chores) that aided adult children, siblings, grandchildren and elderly parents. A framework (Figure 1) emerged from the analysis that depicts informants' consumption experiences as coloured by intergenerational support and ambivalence. These experiences are discussed in the next sections ${ }^{2}$.

\section{Objects/activities as 'reflectors of egoism'}

The first type of ambivalence centres on objects or activities experienced as 'reflectors of egoism'. Informants often expressed negative feelings like guilt and shame with positive feelings for their valued possessions and activities because these either impeded further support for the family or required additional support from the family. For example, Vivian

\footnotetext{
${ }^{2}$ Since the focus of this paper is consumer ambivalence, participants' predominately positive experiences with possessions and activities are not included. However, some goods (e.g., goods that improved job prospects and consumption simplicity) were experienced only on a positive level as favouring individual, relational or collective family identities, not at the expense of one another.
} 
(aged 67) felt guilty for buying herself a dress instead of spending the money on her two unemployed daughters, aged 35 and 39. The dress objectified her guilt for favouring personal identity over relational and collective family identities. An internal locus of control intensified these feelings of guilt as Vivian felt partly responsible for her daughters' unemployment. At the same time, the fact that Vivian had not bought any clothes for herself in two years as 'the expenses are so many due to the daughters' unemployment', and that her daughters insisted on the dress purchase, contributed to her positive feelings about the dress. Reflecting intergenerational ambivalence, Vivian expressed mixed feelings toward consumption goods like her new dress. She said:

[Our daughters] are both unemployed and we are supporting them. [...]All these [bills] are depriving us of a lot of things.[...] We started off with other prospects and we ended up counting our money and not knowing how to manage[...]I was submissive to my parents, my parents-in-law, my husband, my children[...] What 
Figure 1: Consumption experiences coloured by familial intergenerational support and sharing within a context of increased economic difficulty

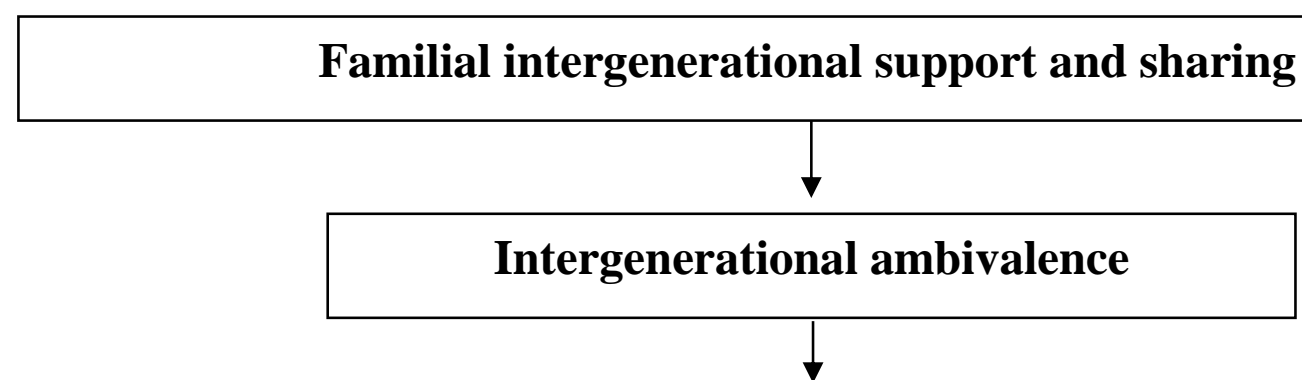

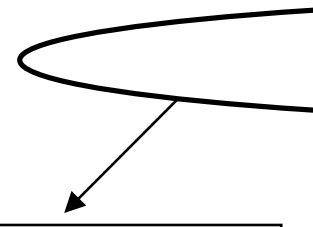

\section{'Reflectors of egoism'}

Ambivalence and doubts about objects/activities that objectified shame and guilt for favouring individual identity over relational and collective identities
Possessions/products/consumption activities experienced as:

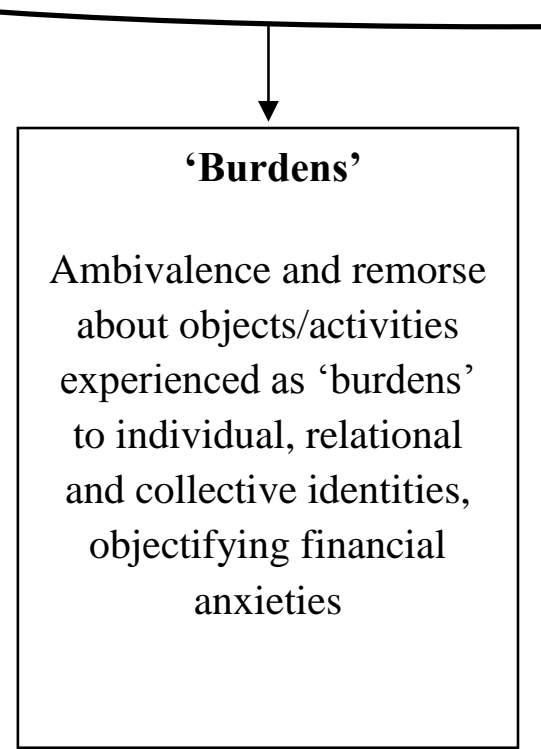

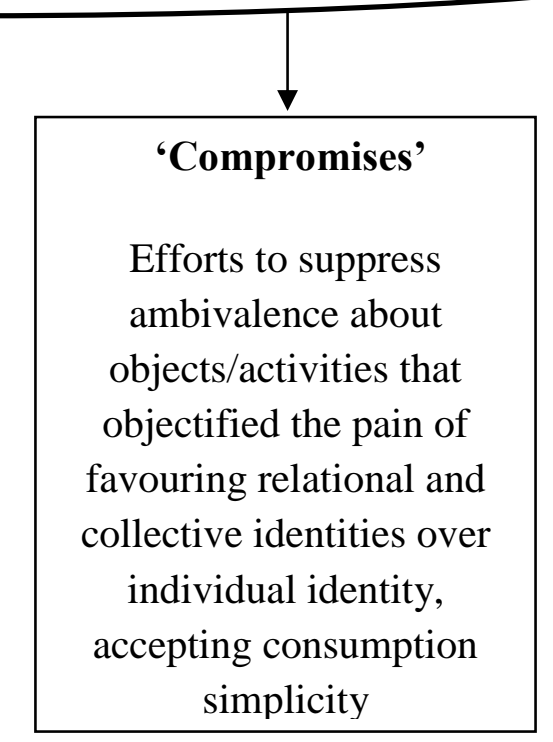

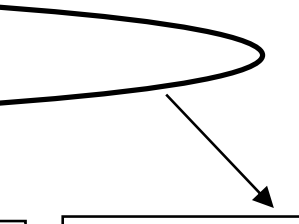

\section{'Lost self-extensions'}

Some objects/activities that were extensions of self were abandoned (albeit with ambivalent feelings) in order to favour relational and collective identities by abandoning an individual identity 
about me? I won't get to live? [...] but it's impossible for my daughters to find a job due to unemployment [...] I felt guilty for buying the dress. I could buy something for my daughters instead [...] I didn't want my daughter to leave the city and I affected her. Now, I see it as a solution for her to have a job.

Vivian's comment regarding she and her husband starting off with other prospects reflected her prior expectations for better personal financial prospects and for her adult children's financial independence, both unmet due to increased unemployment (Eurostat, 2012/2013/2014). This generated ambivalence for some goods. At the time of her interview, Vivian engaged not only in downward sharing (sharing with her adult children), but also in upward sharing as she also supported her elderly father who lived nearby. She cooked meals and did household tasks and grocery shopping for him. Vivian had ambivalent feelings about the day trips she made with her husband. On the one hand, she felt positive about the day trips as these provided short escapes and recreation, but on the other hand she felt guilty for leaving her father alone. Reflecting intergenerational ambivalence, she said:

My father has clung on to me; he's suffocating me at times. I feel sorry for him; he is 98 years old. He's all alone. I try but I also feel guilty that I should be there for him more. He is making me feel guilty asking me to stay longer even though I'm with him several hours daily.

Another example was Laura (aged 34) whose 30-year-old brother moved in with her after becoming unemployed. Laura supported him financially and cut down on her own expenses to relieve her parents, who also experienced financial difficulties, of the anxiety of financially supporting her brother. Laura's sideways sharing with her brother was simultaneously indirect upward sharing with her parents. Laura felt that the clothes she had purchased recently not only enabled her to feel beautiful, receive positive comments and lift her mood but they also increased her feelings of being egocentric, and intensified the financial anxieties and fears she experienced in her efforts to financially support her brother. Overall, this type of consumption caused mixed feelings among consumers, reflected intergenerational ambivalence (e.g., Willson et al., 2003), and heightened consumption fears (i.e., fears of harming through consumption; Voice group, 2010).

Moreover, many informants who were being supported by their families had mixed feelings about their valued possessions and activities, as these often represented others' sacrifices and 
their own guilt and shame for favouring personal rather than relational or collective identities (e.g., Nancy, Elsa). Such goods were experienced as ranging in the middle of the necessityluxury continuum. For instance, participants (e.g., Dennis, Christopher, Amanda) expressed ambivalent feelings for their studies in their favourite subject areas because they received financial support from their families that allowed them to study. Reflecting mutual caring, they felt their parents had sacrificed themselves for them and by studying they acted in egoistic, inconsiderate ways. Another example is Mark (aged 37) who returned to his parents' house and felt shame for receiving parental support, meaning that he experienced many of the products and services he consumed with ambivalent feelings. He said:

I'm ashamed I live in my parents' house. When I was self-sufficient I was paying for my health insurance but since I became unemployed my father does...I didn't want him to pay; it's an issue of dignity but if something bad happens we wouldn't be able to deal with it.

It should be noted that Mark felt in part responsible for his financial difficulties and that his internal locus of control and his prior expectations for achieving financial independence intensified his feelings of shame and guilt. Belk (2010) discussed the lack of reciprocity in sharing, where no one keeps track of the balance between giving and receiving. Sharing may not impose an obligation for reciprocity but participants in this study kept track of intergenerational sharing, especially when they were the recipients of it. In alignment with Arnould and Rose's (2015) notion of mutuality or generalised reciprocity, the recipients of intergenerational support were both willing and expected to act similarly if the circumstances were reversed and the providers were in need of support.

At the same time, several participants (e.g., Mark, Simon) who received support from family members, especially those who returned to the parental house, expressed feelings of being oppressed by their supporters. They valued goods that enabled 'me-time' away from their families, and made 'space' for them within or outside their homes (e.g., books, bicycle, gym, gardening, cinema) (Stevens et al., 2003). Participants who stressed the importance of getting away from the family setting (e.g., because they had a car), often made heartfelt appeals asking to maintain existing social ties with friends and distant acquaintances, and to continue to operate in small worlds (Gainer, 1995). However, such consumption often required receiving support from the family, and thereby caused guilt for favouring personal identity over relational and collective identities. For example, Nancy (aged 35) had to leave the house 
she was renting when she became unemployed and move in with her sister. She valued her car for enabling a sense of independence, but she also felt guilty for receiving support from her parents to maintain it because they had financial difficulties of their own.

The mixed feelings of gratitude and guilt that recipients of intergenerational support feel for consuming goods that are essentially 'reflectors of egoism', can fuel 'compliance' consumption in an effort to please the family members providing sacrificial aid. An example of this was Amanda (aged 32). Amanda felt ambivalent about her house. She worked fulltime and long-hours but was living on a tight budget and had difficulties making ends meet. She felt guilty because her father was also experiencing financial difficulties but was helping her financially by paying her mortgage (which she had taken out on the assumption of better financial conditions before the financial crisis). Amanda's mother, who also had financial difficulties, supported Amanda financially and practically (with things like food baskets). Amanda planned to take a second job. Her house objectified her parents' sacrifice, her selfcriticism about being selfish and uncaring, and her anxiety about the mortgage payment. Reflecting mutuality and concern for her parents, she said:

[My father's] pension has gone down by 50\%. He said, "I can't manage." And what can I say? "Don't live so that I can live?" That's not possible. It's egoistic. I feel bad.

The gratitude and guilt Amanda felt toward her parents reinforced her efforts to engage in activities that pleased her mother (dieting, exercising, hair treatments) and to regulate feelings of intergenerational ambivalence. She said:

I want to improve myself a bit so I don't have to listen to her and her circle's complaints. For example, that my hair is dry and my body isn't toned.[...] when I'm away from my mother's environment, I don't care.[....] But I want to tone up my body and improve my hair and appearance, so that I'm a bit more comfortable in terms of how my mother accepts me.

Overall, ambivalence about consumption that was experienced as favouring personal over relational or collective identities was accompanied by indecision about whether to buy (Otnes et al., 1997), keep, dispose of or sell goods. Some participants tried to deal with these ambivalent feelings and doubts by reducing their use of and sharing the possessions that were "reflectors of egoism" with family members (e.g., Nancy and Simon reduced their use of and shared their cars). Some participants tried to escape the market of 'reflector of egoism' goods 
to eliminate temptation and avoid credit use. The strategy of market avoidance resonated with the strategies of consumer resistance, withdrawal and defiant non-consumption in previous studies (Otnes et al., 1997; Voice group, 2010). At the same time, participants contemplated 'reflectors of egoism' purchases, and engaged in extensive market search and price comparisons that generated further ambivalence due to product and information overload (Otnes et al., 1997). Guilty feelings for 'reflectors of egoism' goods can fuel the 'compliance' consumption (e.g., Amanda's dieting and exercising to please her mother) that generates further ambivalence.

\section{Objects/Activities as 'Burdens'}

The second type of ambivalence related to objects or activities that are experienced as burdens. These were things often acquired with credit or requiring financial resources to operate and maintain, which create financial pressures, stress, fears and feelings of regret within the context of intergenerational support. These objects and activities are experienced as partly supporting (to some degree) but predominantly burdening individual, relational and collective identities. They are experienced as embodying an agency that made them oppressive, objectifying concerns and pressures, demanding care and financial resources and detracting from the care that could be devoted to the self and other family members. The findings reflect debtors' 'imprisonment' (Bernthal, Crockett, \& Rose, 2005) suggesting that the financialisation of consumption can displace the fire of desire (Peñaloza \& Barnhart, 2011). For example, Vivian experienced her car as a burden and, reflecting intergenerational ambivalence, said:

we don't know how to manage paying the instalments...It's got us to a dead end...You try to support your family, your children who live in a different house; it's very hard.

Although Vivian felt that the car offered her and her husband short escapes to the countryside, supporting individual and relational identities, she also experienced the car as a 'burden' to her individual and collective identities. Her internal locus of control (she felt partly responsible for her daughter's unemployment) intensified her negative feelings for her burdensome possession. Participants like Alec also expressed feelings of guilt for receiving financial intergenerational support to pay for expenses related to possessions like cars that were experienced as 'burdens'. Some participants also saw their houses (first and especially 
second houses they let for additional income e.g., Alberta) as 'burdens' due to the increasing need to provide or receive intergenerational support, and to other factors (like the pain of mortgage payments and the houses' reduced value). For example, Vivian experienced the 54 sqm flat she inherited with her sister-in-law as a burden due to increased taxation, reduced rent, reduced saleability and increased need to provide financial support to her adult daughters, as well as the need for house restoration and its resulting task overload (Otnes et al., 1997; Voice group, 2010) as she was providing practical support to her elderly father.

It should be noted that participants had acquired 'burden' goods often due to prior expectations about adult children's financial independence and about better financial conditions. However, the reality of intergenerational support and financial difficulties generated participants' ambivalent feelings for these goods. These goods were often acquired before the announcement of the first austerity measures. They were often previously viewed as necessities but were then viewed as luxuries due to the experience of financial difficulties.

It should be noted that the supporter and the receiver of support may each view the latter's possessions differently. For instance, as discussed in the previous section, the receiver may view his/her car as a reflector of egoism, being ranged in the middle of the necessity-luxury categorisation, for enabling a degree of much desired independence (e.g., Nancy and her car). However, the supporter may view the car of the receiver of support as a luxury and a burden. For example, Vivian viewed some of her adult daughter's activities and goods (including her new car) as luxuries and burdens. She said:

My daughter's ex-husband emptied her house and they started saying, "buy livingroom furniture, a television, help her replace her car, send her to water sports and to a second University program" that cost a lot.[...] Now, things are tight...I personally don't want a lot of things, only the basic[...]Now, she's again in a wrong relationship. She's better off being alone rather than being self-destructive with this person because when she breaks up we have psychologists and stuff.

It is interesting to note Vivian's frustration in the quote above concerning the fact that despite sharing her resources with her adult daughter she cannot control her daughter's life choices. The findings indicate that intergenerational support reinforced the loss of financial control experienced through the acquisition (and consumption) process, and undermined the advantage that goods can provide in gaining a sense of control. Instead these were 
experienced as 'burdens' (Belk, 2007), reflecting intergenerational ambivalence. This resulted in the informants attempting to reduce expenses by cutting back on the use of or sharing their cars, or even researching the market in an effort to sell their properties. Some moved to a smaller house to be closer to work (to eliminate the need for a car) and engaged in a materially simpler lifestyle.

\section{Objects/Activities as 'Compromises'}

The final type of ambivalence concerns two characteristics: 1) compromises and 2) lost selfextensions (detailed in the following section). Some participants (e.g., Luke) expressed ambivalent feelings for certain types of consumption because it not only symbolised providing support to their relatives but also because it represented compromise in the form of requiring them to lower their own living standards. The quality of the products (often experienced as necessities) that resulted from these compromises was not particularly appreciated, but informants felt positive about the fact that their lower purchase prices allowed them to provide more intergenerational support. Such consumption objectified the self-sacrificial pain of favouring relational and collective identities over personal identity. For example, Diana (aged 50), expressed mixed feelings about the cheaper cosmetics she had to buy as a result of caring for her family. She felt that while these products enabled her to provide more financial support to her daughter and grandson who had recently moved in with her, the low quality of the cosmetics was not effective in helping her look beautiful and young. Diana said:

We get by with great difficulty financially now. She doesn't get alimony for the baby...She also works, at a very tiring job and we're struggling to get by, to survive. With difficulty we make a dish of food.[...] sometimes it's not enough to get through the month.[...] My grandson is without a father and I say, "God help me to be healthy so they aren't left on their own. "[...]I was divorced too with two children; what did the state do for us? Absolutely nothing

Participants' prior expectations for adult, employed children's financial independence and better financial conditions contributed to their negative feelings about compromising via lower living standards. Note how Diana tried to suppress the intergenerational ambivalence that started to emerge as a result of the sacrificial compromise of providing support to her 
adult child by conceding that she was providing support to her underage grandchild. As underage children are not expected to be financially independent, sharing with underage children generates less ambivalence than adult intergenerational sharing. Like Diana, in attempts to curtail feelings of intergenerational ambivalence, several participants attributed compromises to the recession and weak welfare state (Eurostat, 2012/2013/2014; Gal, 2010). Participants also made compromises while supporting family members as a result of task overload. For example, George compromised by choosing to undertake very few recreational activities in favour of supporting his son by working long hours without pay at his son's company.

Some participants (e.g., Nicky, Nick) had to make lifestyle and consumption compromises (e.g., moving to less expensive, smaller or older houses in noisy neighbourhoods they considered dangerous or dirty) to reduce their expenses and release their relatives from the anxiety of providing financial support. Similarly, as the following quotes indicate, participants who started or continued to live with relatives (e.g., Debbie, Nancy) experienced both co-habitation and their (new) homes as compromises imposed by economic conditions. Gratitude and simultaneous feelings of personal failure (reflecting an internal locus of control) accompanied informants' decisions to remain or move in with relatives.

I have less work due to the crisis. I get by on my savings. I feel I didn't make it in my life...I'd like to have a house of my own that would suit my needs. I now share a very small house with my mother. It's really difficult. There's always the other person's presence and her needs; it's a big compromise (Beatrice, aged 55)

I used to say to my best friend who was whinging that we were still living with our parents, "Be patient; four more years (until graduation) and then we're going to live alone". This was the plan before or at the start of the crisis. This plan was upset...It's very helpful to...find a plate full of food when you come back tired from work, it's true. But it's also annoying when they (parents) ask you "what time did you come back home last night?" It's difficult. You're never free in your own space. You're in the same house and they ask "where were you?" and... "what's this?" and... "why is this here?" (Tina, aged 23)

Note in the quotes above, that the participants' unmet expectations for better financial conditions and independence contributed to ambivalence for 'compromises'. 
This type of consumer ambivalence was not accompanied by indecision regarding continuing the behaviour. An internal locus of control facilitated acceptance of 'compromises' as participants tried to suppress their negative feelings and accept consumption simplicity. Participants often asked for others' assistance in finding the best possible 'compromise' goods; and engaged in trial and error and extensive market search (Otnes et al., 1997; Voice group, 2010). This led, however, to feeling overwhelmed due to product, information and task overload. In Otnes et al.'s (1997) non-constrained financial context of planning a sociocultural significant event (i.e., a wedding) and in the Voice's group (2010) context of the transitioning into motherhood, product overabundance emerged as a direct antecedent of consumer ambivalence. In this paper's context of financial constraint, product overabundance emerged more indirectly as a consequence of extensive market search that was a strategy to cope with consumer ambivalence (regarding reflectors of egoism and compromise goods). This suggests that in an effort to cope with consumption ambivalence, consumers may enter into a vicious cycle that generates further ambivalence.

\section{Objects/Activities as 'lost extensions of the self'}

The second characteristic of the final type of ambivalence relates to objects or activities that are experienced as lost extensions of the self. These items are frequently experienced as luxuries. For instance, informants (e.g., Mark, Diana, Luke, Vivian, Paul) expressed ambivalence at being forced to abandon favourite activities or sell beloved possessions that were part of their extended selves in order to raise resources for themselves and their families. This often required them to abandon their personal identities in favour of relational and collective identities (Belk, 1988). For example, Alberta (aged 60) reflected intergenerational ambivalence when she expressed her disappointment in not being able to travel anymore, due in part to supporting her daughter. She said:

I paid the tuition for her to continue studying (abroad), but she returned and started working under a contract. As a result, while she could have finished with her studies in 2008 or 2009, and she could have also managed to find a permanent job, she didn't. In 2009, her contract wasn't renewed. She gave up and now she's abroad studying and working but her job isn't relevant to her studies and doesn't give her financial security. Her future worries me...she should think about what she'll do. But 
she doesn't want to talk about this with me. This uncertainty displeases me; upsets me and pressures me.

Remarkable is Alberta's frustration at not being in control of her adult daughter's choices despite supporting her financially. Another example is George (aged 69) who expressed his disappointment at being forced to abandon favourite activities (e.g., trips, cinema) in order to support his adult children. He said:

I'm now forced to help my children (aged 35, 33 and 26)... They are grown up. They should be self-sufficient...They haven't cut their umbilical cords yet.[...] they have jobs but due to the financial crisis none of them is fully self-sufficient.

Note George's unmet expectation that adult children should be financially self-sufficient, which intensified his negative feelings for the loss of his self-extension activities. Several participants like George tried to curtail their intergenerational ambivalence by considering the economic conditions (e.g., Eurostat, 2012/2013/2014), thereby justifying providing support for their family members.

Participants receiving intergenerational support also lost self-extensions as a result of their desire to relieve their relatives of the burden of their support, and to prevent or curtail others' intergenerational ambivalence. For example, Amanda sold her cherished camera though it symbolised an important personal identity for her. Selling her camera was a way to make ends meet and unburden her family. Another example was Nicky (aged 43), who sold her house, a cherished possession, as a way to release her family from the financial anxiety of supporting her (and in turn providing for her family members, reflecting concern for them, mutuality and indirect reciprocity; Arnould \& Rose, 2015). She moved into her counselling office and put most of her cherished possessions into storage. She said:

I sold my home. I experienced this with mourning.[...] When I bought it I thought I'd live there all my life; it had a garden, it wasn't in the middle of noise and air pollution.[...]I suddenly found myself living in the city centre in a small flat[...] I can't get any fresh air, the atmosphere here bothers me greatly; the centre is abandoned[...]I was recently robbed here[...]I was left with no ID[...]I had my personal heirlooms which I took to a storage room. I buried them...I was forced to.[...] they've great sentimental value; things from my father and mother, photographs, heirlooms, music records, gifts.[...]There's no place for them 
here.[...]I'm sad. It was a loss.[...] to adapt I want to build more inner objects of sentimental, psychological and intellectual value; these are the freedom and values nobody can take away from us.

Note Nicky's prior belief, based on her unmet expectations for better financial conditions, that she would live in her former house all her life. This finding indicates that feelings of selfloss emerge not only when losing possessions (e.g., Belk, 1988; Sayre, 1994), but also when being forced to store them. Several informants were forced to store possessions when they moved in with family members, and expressed concerns that they would not be able to retrieve these self-extension possessions from storage, especially the informants considering moving abroad. Nicky experienced her cherished possessions in storage as lost rather than temporarily absent from her life since she did not feel there was a realistic prospect of retrieving them from storage. By contrast, in Sayre's (1994) study, fire victims experienced lost objects as being 'missing or absent' rather than being lost, as insurance enabled them to replace their lost possessions. Possessions that are experienced as being irreplaceable (e.g., associated with loved ones) (e.g., Grayson \& Shulman, 2000), and are sold or stored without the prospect of retrieving them from storage are experienced as lost, while possessions that are in fact lost or sold but can be easily replaced, especially in the near future, are experienced as absent.

As in Elliott's (1995) study, Nicky and these downwardly mobile consumers discussed the merits of a life of 'voluntary simplicity', and encouraged themselves to ameliorate painful feelings of sadness and self-loss that emerged from being forced to abandon favourite activities or sell or store loved possessions. To this end, they avoided the market of the 'lost self-extension' good. In the case of 'lost self-extension' (and 'compromise') goods, simplified consumption was more accurately construed as involuntary simplicity (Rudmin \& Kilbourne, 1996) imposed by external conditions. Participants' efforts to accept consumption simplicity resonated with strategies of endurance (Voice group, 2010), toughing it out and assertiveness (asserting that this was the right course of action) (Otnes et al., 1997).

The loss of goods that are self-extensions is also relevant to task overload. Nicky, for example, lost self-extension activities (e.g., trips), due to task overload in support of her elderly mother, e.g., cooking meals, doing household tasks, grocery and other shopping. She said: 
It's very hard for my 80-year-old mother to move about; she needs a person to go shopping for her and do the chores. She lives off a very small pension and she has a financial insecurity along with the anxiety of dying and her loneliness...[Getting] Medication and medical care is like going through hell now for these people.

In Otnes et al.'s (1997) study, consumer ambivalence often stemmed from task overload that resulted from preparing for a socio-culturally significant event (i.e., a wedding) that was relevant to a marketplace of non-financial constraint. In our study, consumer ambivalence often stemmed from task overload that resulted from undertaking multiple responsibilities in an effort to support family members or release them from the anxiety of providing support.

\section{Types of family sharing}

Sharing can be identified by type (see Figure 2). Participants engaged in downward sharing (e.g., parents sharing with adult children) and upward sharing (e.g., adults sharing with their parents), as Belk (2010, p.725) briefly suggested but did not empirically examine. Upward sharing predominantly took the form of sharing material, time and care resources and was less about sharing financial resources. As Belk (2010) pointed out, the amounts adult children give to their parents are considerably less than the amounts parents give to their children. Sideways sharing (sharing with siblings) can be seen in some cases as indirect upward sharing (to release parents from downward sharing).

Belk (2010/2014) also made a distinction between the inclusive phenomenon of 'sharing in' and the more charity-like phenomenon of 'sharing out'. When we share in, we make those with whom we are sharing a part of our extended selves. When we share out this incorporation does not take place and the self/other boundary is preserved. Sharing in and sharing out correspond to in-groups and out-groups. Sharing in is an expression of community as it dissolves the interpersonal boundaries posed by materialism and possession attachment and expands the aggregate extended self by expanding the domain of common property. Sharing in involves regarding ownership as common, while sharing out is closer to gift-giving and commodity exchange. Moreover, sharing out may occur when sharing becomes a discretionary choice. 
Downward sharing with adult children can be seen as 'sharing out' as adult children are not under parents' control (e.g., Alberta and Vivian cannot control their adult daughters' life choices), and may therefore be experienced as separate selves. Also, sharing with adult children can be experienced as a matter of choice and therefore as charity-like 'sharing out' due to expectations about adult children's financial independence.

Participants tried to make sharing out more intimate by engaging in family identityconstituting practices and rituals with their adult children like daily family meals. More specifically, even in cases where family members were not living in the same house, they often ate together on a daily basis, especially when living in close proximity. For example, Vivian (aged 67) cooked not only for herself and her husband but also for her father and her adult daughters who lived close by. George's adult children, who did not live with him, ate on a daily basis with George and his wife. They experienced the daily family meal as a way to provide and receive practical and emotional support, which can be viewed as a way to strengthen connections between family members and foster feelings of belonging and solidarity. It also helped as a way to revise, reconstruct and reinforce the family identity by grounding individuals in a stable nurturing space that stands in contrast to their uncertain recessionary environment. As Gainer (1995) pointed out, shared consumption activities and rituals (like the family meal) can be used to symbolically demonstrate membership in collectives and inclusion in small worlds, and to foster and maintain both intimate and more distant relationships. Gainer (1995) discussed the importance of relational symbolism linked to the consumption of the arts. The data collected herein emphasises the importance of relational symbolism across a variety of product categories, and the role consumption choices play in identity projects within and outside of the family. It should also be mentioned that sharing with adult children renegotiated status differentials among family generations and contributed to changing family identities. The social-hierarchical dimension of a status transition (downward mobility here) includes a reconfiguration of capital (Bourdieu, 1984; Ulver \& Ostberg, 2014). For example, the nouveaux riches try to compensate for their lack of cultural and social capital with economic capital (Belk, 1986 in Ulver \& Ostberg, 2014). In this study, recipients of intergenerational support tried to offset their lack of economic capital with social capital.

Downward sharing with underage children or grandchildren was experienced as 'sharing in' because sharing in these circumstances was seen as a matter of entitlement. This is because, 
adults (e.g., Debbie, Alec, Diana) were firmly in control of young children who were vulnerable, i.e., not in control of their own lives and dependent upon adults. Sharing in may therefore take place as underage children or grandchildren may not be experienced as separate selves from their adult supporters.

Upward sharing with parents was experienced as 'sharing in' when parents were elderly and in poor health and therefore vulnerable and not in control of their lives (e.g., Vivian's father and Nicky's mother), or when parents were in poor financial states and not able to manage their own financial risks, e.g., Laura's merchant parents. In these cases, upward sharing was experienced as 'sharing in' because sharing was seen as obligatory, i.e., others' requests cannot be denied and sharing is the only choice, especially in a weak welfare state.

Upward sharing with parents who are neither vulnerable nor at risk can be experienced as 'sharing out'. Upward sharing with older relatives (e.g., uncles, aunts) can similarly be experienced as 'sharing out' because distant relatives can be considered out-groups, to which sharing out corresponds.

Figure 2: Types of sharing

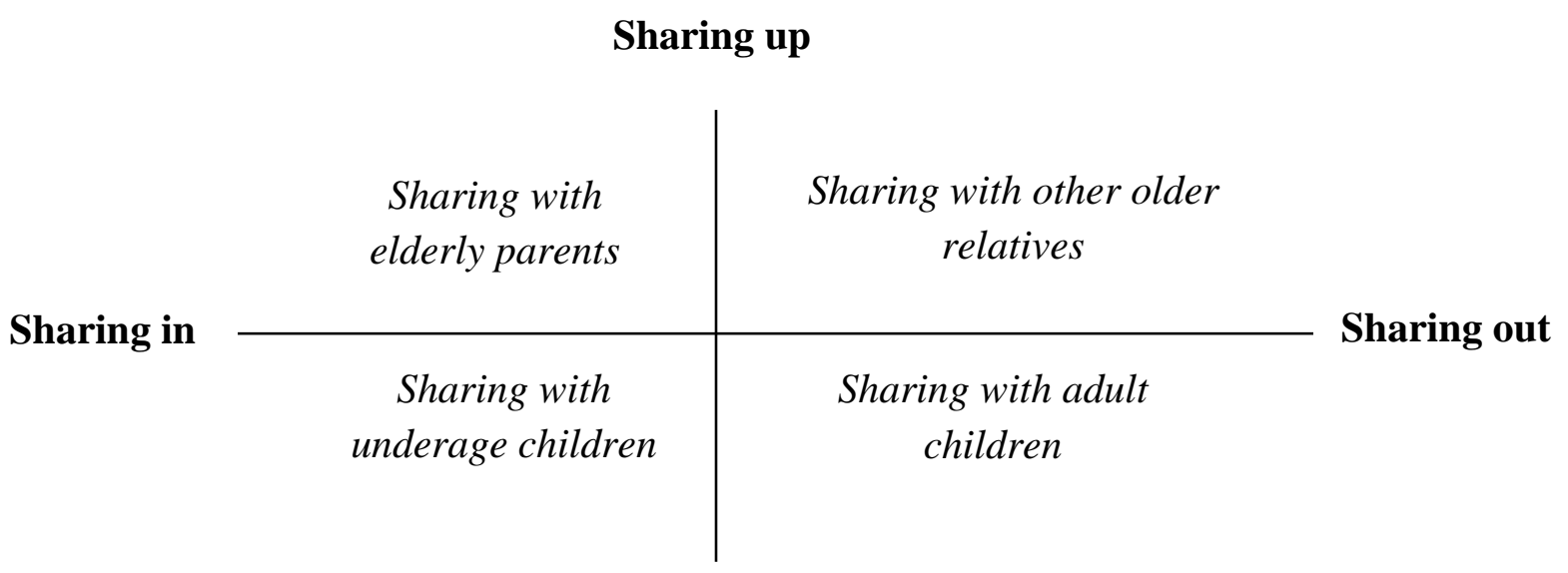

Sharing down

\section{Coping with ambivalence}

Three types of consumer ambivalence were identified: a) guilt/shame-evoking consumption of 'reflectors of egoism' goods, b) regretful consumption of 'burdensome' goods, and c) 
involuntary simplicity with 'compromises' and 'lost self-extensions'. Table 2 below summarises the ways in which consumers cope with these types of ambivalence. Though some of the strategies participants undertook to cope with ambivalence were the same for all three types of consumer ambivalence identified, certain characteristics of consumer ambivalence and some of the coping strategies were specific to each type of consumer ambivalence.

Table 2 here

\section{CONCLUSION}

This paper interweaves three major consumer research concepts: 1) ambivalence (Otnes et al., 1997), 2) sharing (Belk, 2007/2010/2014), and 3) family identity (Epp \& Price, 2008/2010), within the neglected context of familial adult intergenerational support, and extends previous consumer research in the following ways.

This research adds to previous consumer research on families that presented more polarised (i.e., positive versus bleak) (e.g., Hamilton \& Catterall, 2006; Hill \& Gaines, 2007) views of the family by revealing the more diverse, complex and ambivalent feelings associated with family relationships and consumption, and highlighting the relevance of the sociological concept of intergenerational ambivalence, (e.g., Lüscher, 2011; Lüscher \& Pillemer, 1998) to consumer studies. Intergenerational ambivalence accompanied intergenerational support and was the lens through which these downwardly mobile consumers experienced consumption. This paper therefore adds to previous work that explored antecedents to consumer ambivalence (Otnes et al., 1997) by shedding light on family sharing, particularly adult intergenerational support in situations of economic adversity, as a major antecedent to consumer ambivalence.

This paper further underscores the internal conflict between individual, relational and collective identities (Epp \& Price, 2008/2010) as a major antecedent to consumer ambivalence, e.g., Otnes et al., 1997; Voice Group, 2010. The paper extends Epp and Price's (2008) argument that identity bundles may in some situations be inconsistent, and does so by exploring and mapping the consumer dilemmas and individual, relational and collective identity pursuits in intergenerational sharing that concern intergenerational ambivalence. Participants' intrapersonal conflicts may be a way to reduce or even prevent the external, interpersonal conflicts that emerge due to family members' competing needs and wants 
(Otnes et al., 1997). Interpersonal conflict may be too costly (e.g., in emotional terms) within the downwardly mobile contexts of increasing financial constraint and uncertainty.

This paper additionally extends both Otnes et al.'s (1997) argument that consumer ambivalence in a non-constrained financial context stems from consumers' unmet product/retailer-specific expectations, and the Voice's group (2010) finding that consumer ambivalence stems from constraints that lead to unrealized consumption aspirations. This study existed within the context of downwardly mobile financial constraints in which consumer ambivalence often results from unmet expectations about adult children's financial independence, i.e., better financial conditions for adult children.

Moreover, the findings reveal three types of consumer ambivalence (e.g., Otnes et al., 1997) within the realm of family sharing. The first type of consumption ambivalence is experienced for goods that prioritize individual over relational and collective identities. In this case, participants reflecting intergenerational ambivalence were involved in the guilt- or shameevoking consumption of goods considered 'reflectors of egoism'. This type of consumer ambivalence was accompanied by doubts about the consumption that were addressed by reducing the use of or sharing the possession in an effort to pursue voluntary simplicity. Participants tried to avoid the market for 'reflector of egoism' goods in order to avoid 'temptations', but often instead engaged in searching for these goods via extensive market search and price comparisons. This type of consumer ambivalence sometimes stimulated 'compliance' consumption.

The second type of consumer ambivalence is experienced for goods that partly support but mainly burden individual, relational and collective identities. Participants engaged in regretful consumption and reflecting intergenerational ambivalence experienced some goods as 'burdens'. This type of consumer ambivalence is accompanied by remorse for the consumption, which is often addressed by reducing the use of, sharing or trying to sell the possession in an effort to pursue voluntary simplicity.

The third type of ambivalence is experienced for consumption that prioritises relational or collective identities over individual identity. Here participants engaged in involuntary simplicity and experienced intergenerational ambivalence by accepting 'compromises' and giving up possessions which represented 'self-extensions'. This type of consumer ambivalence is not accompanied by doubts about the continuation of the behaviour but rather 
by efforts to accept consumption simplicity. To this end, participants avoided the market for 'lost self-extensions' goods and engaged in extensive market search to find the best possible 'compromise' goods. An internal locus of control facilitated the acceptance of 'compromises' and the acceptance of losses.

This paper also extends previous work (e.g., Otnes et al., 1997; Voice group, 2010) by proposing a typology of coping strategies along a practical/emotional continuum (Table 2) and revealing the following as ways to cope with consumer ambivalence: reduced use and sharing of goods, efforts to sell goods, internal locus of control and constraints attributable to the recessionary environment and weak welfare state. This study additionally empirically examines upward and downward sharing and identified different types of sharing (Figure 2) that extend Belk's (2007/2010/2014) work on sharing and support the notion of mutuality (Arnould \& Rose, 2015).

Consumer research usually applies two family paradigms (i.e., solidarity and conflict) but these are challenged by the ambivalence paradigm by way of the mixed feelings that occur in family relationships (Lüscher \& Pillemer, 1998). The ambivalence perspective offers direction for future consumer research. For example, research can explore ambivalence and family sharing within different family structures and during different family transitions. Future research can also examine sharing, ambivalence and mutuality outside the family, e.g., within a brand community.

This study's findings provide insights into the potentially difficult experiences that downwardly mobile consumers who are transitioning into intergenerational support may have in societies with weakened welfare states like other Southern European countries. Future research should investigate how these findings might resonate in societies with stronger welfare states or in states less affected by austerity measures but that are nevertheless experiencing significant rises in intergenerational support (e.g., ONS, 2014) despite possibly higher cultural expectations for adult children's financial independence.

Future research could also examine how these findings would resonate in Greece and other Southern European Societies in the case of Grexit. The latter would bring a deep recession, with rising unemployment, falling incomes and a new currency threatening further instability and making a recovery even more unlikely (e.g., Gnath \& Hoffmann, 2015). The Greek people would also have to pay for Greece's exit out of the Eurozone with imports (e.g., food, 
drugs) becoming prohibitively expensive and creating a social disaster as the Greek economy breaks down (e.g., Fischer \& Pastore, 2015; Gnath \& Hoffmann, 2015).

If Greece were to leave the Eurozone, given the inevitable uncertainty that would follow a Greek exit, a domino effect in other countries could take place. Countries like Ireland and Portugal, could be dragged back into crisis (Fischer \& Pastore, 2015). Ultimately, Greece exit from the Euro zone could jeopardize the European ideal itself. The EU approval ratings continue to sink both in Greece and in the other countries of the euro area. Insisting on a speedy repayment of debts in the case of Greece, with tight and inflexible deadlines, would not only affect Greece, but also such 'punishing' behaviour could be a fertilizer for the growing influence of nationalist parties in European countries (Fischer \& Pastore, 2015). Yet, the EU was founded to destroy nationalisms that have caused wars for years in Europe. Besides, only through re-building a stable economy and achieving growth will Greece be able to pay back its debts (Fischer \& Pastore, 2015).

Marketing managers need to analyse and understand the intergenerational ambivalence that often accompanies intergenerational support and how it colours consumption experiences, and use this information to develop product and communication strategies. Practitioners should be concerned with how to turn goods experienced as 'reflectors of egoism', 'burdens' or 'compromises' into goods that support, not negate, individual, relational and collective identities. As meanings attributed to goods can change (e.g., Karanika \& Hogg, 2013), practitioners also need to assess the conditions under which goods experienced as 'reflectors of egoism' or 'burdens' might be abandoned (and turned into 'lost self-extensions') and take action to prevent them. Attention must be paid to the varying types of consumer ambivalence as each has different characteristics that lead to different coping strategies. Finally, in an effort to better inform interventions at the societal, family and individual levels, this study could be of value to policy makers who need to understand recessionary familial intergenerational support and the feelings of ambivalence and consumption behaviours that accompany it. 


\section{REFERENCES}

Arnould, E.J., \& Rose, A.S. (2015). Mutuality Critique and substitute for Belk's "sharing". Marketing Theory, 1470593115572669.

Askegaard, S., \& Linnet, J.T. (2011). Towards an epistemology of consumer culture theory Phenomenology and the context of context. Marketing Theory, 11(4), 381-404.

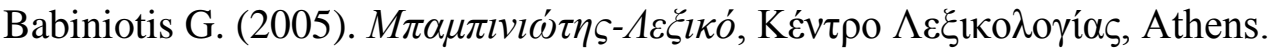

Belk, R.W. (1988). Possessions and the Extended Self. Journal of Consumer Research, 15, 139-67

Belk, R.W. (2007). Why not share rather than own?. The Annals of the American Academy of Political and Social Science, 611(1), 126-140

Belk, R. (2010). Sharing. Journal of Consumer Research, 36(5), 715-734.

Belk, R. (2014). You are what you can access: Sharing and collaborative consumption online. Journal of Business Research, 67(8), 1595-1600.

Belk, R., Llamas, R. (2012), 'The nature and effects of sharing in consumer behavior' in Mick, D.G., Pettigrew, S., Pechmann, C.C., \& Ozanne, J.L. (Eds.). Transformative consumer research for personal and collective well-being. Routledge. 625-64

Bengtson, V.L. (2001). Beyond the nuclear family: The increasing importance of multigenerational bonds. Journal of Marriage and Family, 63(1), 1-16.

Bernthal, M.J., Crockett, D., \& Rose, R.L. (2005). Credit cards as lifestyle facilitators. Journal of Consumer Research, 32(1), 130-145.

Bourdieu, P. (1984), Distinction: A Social Critique of The Judgement of Taste, London, UK:

Routledge.

Cappellini, B., Marilli, A., Parsons, E. (2014). The hidden work of coping: gender and the micro-politics of household consumption in times of austerity. Journal of Marketing Management, 30(15-16), 1597-1624.

Carrigan, M., \& Szmigin, I. (2006). "Mothers of invention": maternal empowerment and convenience consumption. European Journal of Marketing, 40(9/10), 1122-1142.

Chalari, A. (2014). The Subjective Experiences of Three Generations during the Greek Economic Crisis. World Journal of Social Science Research, 1(1), p89.

Elliott, R. (1995). How do the unemployed maintain their identity in a culture of consumption. European Advances in Consumer Research, 2, 273-276.

Epp, A.M., Price, L.L. (2008). Family identity: a framework of identity interplay in consumption practices. Journal of Consumer Research, 35(1), 50-70.

Epp, A.M., Price, L.L. (2010). The storied life of singularized objects: Forces of agency and network transformation. Journal of Consumer Research, 36(5), 820-837.

Eurostat (2012). Euro area unemployment at $11.1 \%$. Retrieved from http://epp.eurostat.ec.europa.eu/cache/ITY_PUBLIC/3-02072012-AP/EN/3-02072012AP-EN.PDF

Eurostat (2013). Living standards falling in most Member States. Retrieved from http://epp.eurostat.ec.europa.eu/cache/ITY_OFFPUB/KS-SF-13-008/EN/KS-SF-13-008EN.PDF

Eurostat (2014). Unemployment statistics. Retrieved from http://epp.eurostat.ec.europa.eu/statistics_explained/index.php/Unemployment_statistics

Fischer, J. A., \& Pastore, F. (2015). Completing the Monetary Union of Europe as mid-term solution of the Euro crisis.

Gainer, B. (1995). Ritual and relationships: interpersonal influences on shared consumption. Journal of Business Research, 32(3), 253-260.

Gal, J. (2010). Is there an extended family of Mediterranean welfare states?. Journal of European Social Policy, 20(4), 283-300. 
Georgas, J. (1989). Changing Family Values in Greece From Collectivist to Individualist. Journal of Cross-Cultural Psychology, 20(1), 80-91

Georgas, J., Mylonas, K., Bafiti, T., Poortinga, Y.H., Christakopoulou, S., Kagitcibasi, C.,...\& Kodiç, Y. (2001). Functional relationships in the nuclear and extended family: a 16-culture study. International Journal of Psychology, 36(5), 289-300.

Gnath, K., \& Hoffmann, I. (2015). Greece After the Referendum: Three Possible Scenarios for the Euro Area. Flashlight Europe $N^{\circ} 7-09$ July 2015.

Götze, E., Prange, C., \& Uhrovska, I. (2009). Children's impact on innovation decision making: a diary study. European Journal of Marketing, 43(1-2), 264-295.

Grayson, K., \& Shulman, D. (2000). Indexicality and the verification function of irreplaceable possessions. Journal of Consumer Research, 27(1), 17-30.

Hamilton, K. (2009). Consumer decision making in low-income families: The case of conflict avoidance. Journal of Consumer Behaviour, 8(5), 252-267.

Hamilton, K., Catterall, M. (2006). Consuming love in poor families: children's influence on consumption decisions. Journal of Marketing Management, 22(9-10), 1031-1052.

Herzfeld, M. (2011). Crisis attack: Impromptu ethnography in the Greek maelstrom. Anthropology Today, 27(5), 22-26.

Hill, R.P. (1991). Homeless women, special possessions, and the meaning of "home". Journal of Consumer Research, 298-310.

Hill, R.P., Gaines, J. (2007). The consumer culture of poverty: behavioral research findings and their implications in an ethnographic context. The Journal of American Culture, 30(1), 81-95.

Hirschon, R. (2001). Freedom, solidarity and obligation. Linguistic politeness across boundaries: The case of Greek and Turkish, 88, 17.

Hogg, M.K., Folkman Curasi, C., Maclaran, P. (2004). The (re-)configuration of production and consumption in empty nest households/families. Consumption Markets \& Culture, 7(3), 239-259.

Karanika, K., \& Hogg, M.K. (2010). The interrelationship between desired and undesired selves and consumption: The case of Greek female consumers' experiences. Journal of Marketing Management, 26(11-12), 1091-1111.

Karanika, K., \& Hogg, M.K. (2013). Trajectories across the lifespan of possession-self relationships. Journal of Business Research, 66(7), 910-916.

Kerrane, B., \& Hogg, M.K. (2013). Shared or non-shared?: Children's different consumer socialisation experiences within the family environment. European Journal of Marketing, 47(3/4), 506-524.

Knight, D.M. (2012). Turn of the screw: Narratives of history and economy in the Greek crisis. Journal of Mediterranean studies, 21(1), 53-76.

Kochuyt, T. (2004). Giving away one's poverty. On the consumption of scarce resources within the family. The Sociological Review, 52(2), 139-161.

Kouremenos, A., Avlonitis, G.J. (1995). The changing consumer in Greece. International Journal of Research in Marketing, 12(5), 435-448.

Kvale, S. (1983). The qualitative research interview: A phenomenological and a hermeneutical mode of understanding. Journal of phenomenological psychology. 14(2), 171-196.

Lüscher, K. (2011). Ambivalence: A "sensitizing construct" for the study and practice of intergenerational relationships. Journal of Intergenerational Relationships, 9(2), 191-206.

Lüscher, K., Pillemer, K. (1998). Intergenerational ambivalence: A new approach to the study of parent-child relations in later life. Journal of Marriage and the Family, 413-425.

Mavrozacharakis, E., \& Tzagarakis, S. (2015). The Greek referendum: an alternative approach. 
Miles, M.B., Huberman, A.M. (1994). Qualitative data analysis: An expanded sourcebook. Sage.

Mittal, B., Royne, M.B. (2010). Consuming as a family: Modes of intergenerational influence on young adults. Journal of Consumer Behaviour, 9(4), 239-257

Olsen, S.O., \& Grunert, K. G. (2010). The role of satisfaction, norms and conflict in families' eating behaviour. European Journal of Marketing, 44(7/8), 1165-1181.

Olsen, S.O., Prebensen, N., \& Larsen, T.A. (2009). Including ambivalence as a basis for benefit segmentation: A study of convenience food in Norway. European Journal of Marketing, 43(5/6), 762-783.

ONS 2014-Office for National Statistics-(UK), Large increase in 20 to 34-year-olds living with parents since 1996. Retrieved from http://www.ons.gov.uk/ons/rel/familydemography/young-adults-living-with-parents/2013/sty-young-adults.html

Otnes, C., Lowrey, T.M., \& Shrum, L.J. (1997). Toward an understanding of consumer ambivalence. Journal of Consumer Research, 24(1), 80-93

Peñaloza, L., Barnhart, M. (2011). Living US capitalism: the normalization of credit/debt. Journal of Consumer Research, 38(4), 743-762

Penz, E., \& Hogg, M.K. (2011). The role of mixed emotions in consumer behaviour: Investigating ambivalence in consumers' experiences of approach-avoidance conflicts in online and offline settings. European Journal of Marketing, 45(1/2), 104-132.

Pollis, A. (1965). Political implications of the modern Greek concept of self. British Journal of Sociology, 29-47.

Rudmin, Floyd \& William Kilbourne (1996), "The Meaning and Morality of Voluntary Simplicity: History and Hypotheses on Deliberately Denied Materialism," in Consumption and Marketing: Macro Dimensions, Russell Belk, Nikhilesh Dholakia, and Aladi Venkatesh, Cincinnati, OH: South-Western, 166-215.

Ruth, J.A., Hsiung, R.O. (2007). A family systems interpretation of how subsistence consumers manage: the case of South Africa. Advances in International Management, 20, 59-87

Sabri, O. (2012). Preliminary investigation of the communication effects of "taboo" themes in advertising. European Journal of Marketing, 46(1/2), 215-236.

Sayre, S. (1994). Possessions and identity in crisis: Meaning and change for victims of the Oakland firestorm. Advances in consumer research, 21(1), 109-114

Stevens, L., Maclaran, P., Brown, S. (2003). "Red Time Is Me Time" Advertising, Ambivalence, and Women's Magazines. Journal of Advertising, 32(1), 35-45.

Stewart, C. (2014). Colonizing the Greek Mind? Indigenous and Exogenous Psychotherapeutics. Colonizing the Greek Mind? The Reception of Western Psychotherapeutics in Greece.

Thompson, C.J. (1996). Caring consumers: gendered consumption meanings and the juggling lifestyle. Journal of Consumer Research, 388-407.

Thompson, C.J., Locander, W.B., Pollio, H.R. (1989). Putting consumer experience back into consumer research: The philosophy and method of existential-phenomenology. Journal of Consumer Research, 133-146.

Traynor, Ian. (2015). Germany urges 'quality over speed' in Greek bailout. The Guardian, 11 August, 23.

Ulver, S., \& Ostberg, J. (2014). Moving up, down or sideways? Exploring consumer experience of identity and status incongruence. European Journal of Marketing, 48(5/6), 833-853.

VOICE Group. (2010). Buying into motherhood? Problematic consumption and ambivalence in transitional phases. Consumption, Markets and Culture, 13(4), 373-397. 
Willson, A.E., Shuey, K.M., Elder, G.H. (2003). Ambivalence in the Relationship of Adult Children to Aging Parents and In-Laws. Journal of Marriage and Family, 65(4), 10551072. 